\title{
Discussion on Application of Noise Power Generation Technology in Ship Engine Rooms
}

\author{
Jiang $\mathrm{Lu}^{1, \mathrm{a}^{*} \text {, Zheng Zhi-wei }} \mathrm{i}^{2, \mathrm{~b}}$ \\ ${ }^{1}$ Shanghai Maritime Academy, Shanghai, Pudong new area , 200120, China \\ ${ }^{2}$ Shanghai Maritime University, Shanghai, Pudong new area , 201306, China \\ ajianglu1006@126.com
}

Keywords: Engine room; Noise; Power generation

Abstract. On the basis of the ship engine room noise analysis, the paper discusses the application of the noise power generation technology in ship engine rooms. According to the available research results about acoustoelectric conversion, it puts forward that the reasonable distribution and installation of noise power generation devices in ship engine rooms, which can effectively reduce the cabin noise pollution, improve the efficiency of acoustoelectric conversion, give full play to the noise power advantage, and improve the efficiency of noise generation.

\section{Introduction}

In the modern industrialized society, the need for energy is becoming bigger and bigger, and the problem of the energy crisis is concerned by more and more people. In the recent yeas, people focus the research view on the available potential energy in the environment, including solar energy, thermal energy, mechanical energy, chemical energy, biological energy and sound energy.

Noise pollution is rather harmful to people's life and health, and the source of noise is very wide. The common sources of noise are machine noise, traffic noise, fan noise, exhaust noise and so on. However, noise is also a kind of potential energy with considerable energy value, especially the objective noise energy in the ship engine room. If we can make use of a sound energy power generation device to transfer the noise in the engine room to electric energy, it can not only reduce the noise in the environment effectively, but also transfer noise pollution to effective energy to use, so we can achieve the purpose of energy-saving and emission-reduction.

\section{Source of noise in ship engine rooms}

We suppose that the rated power of the main engine of some ship engine room is $1200 \mathrm{~kW}$ and the rated speed is $1000 \mathrm{r} / \mathrm{min}$; the diesel generator set has three and one is standby, and the diesel engine is TBD234V6, its rated power is $186 \mathrm{~kW}$ and its rate speed is $1500 \mathrm{r} / \mathrm{min}$; the generator is 1FC6286-4SA45, its rated power is $150 \mathrm{~kW}$. Figure 1 and 2 are respectively the noise pressure level in the each rate center of the rate range of the main engine and the generator set at the rated speed.

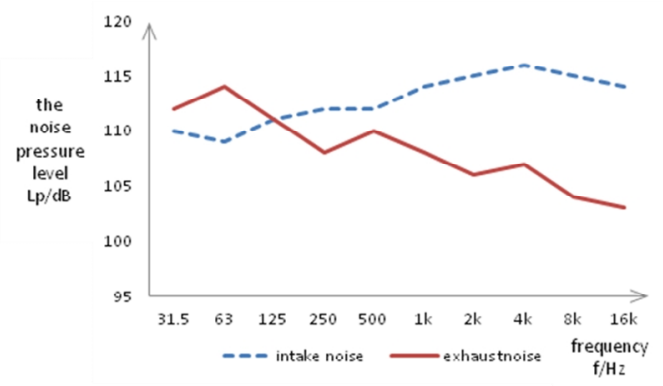

Figure 1 Level of intake and exhaust noise of the main engine

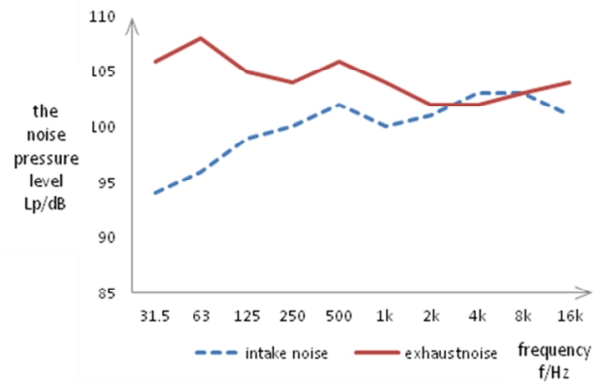

Figure 2 Level of intake and exhaust noise of the generator set 
As we can see in Figure 2, the exhaust noise of the diesel generator set is $106 \mathrm{~dB}$, and its main frequency is $63 \mathrm{~Hz}$ and $125 \mathrm{~Hz}$; the intake noise is more than $103 \mathrm{~dB}$, and its main frequency is $500 \mathrm{~Hz}-$ $16 \mathrm{kHz}$. Therefore, the noise energy is the biggest noise source in the ship engine room, and we can place more receiving devices of sound energy near the main engine according to the need.

Furthermore, because the strong mechanical vibration of machine equipment like the main engine can produce the serious noise energy of low frequency, there is noise of low, intermediate and high frequency in the engine room.

\section{Noise power generation technology}

The earliest acoustic-electric conversion is Bell Phone, the basic principle of which is that diaphragm induces vibration, and it is transferred to different electrical signals. On the other side, the electric signals are transferred to diaphragm vibration sound production of the telephone receiver. At present, the researches about acoustic-electric conversion are mostly based on this basic principle. Among them, the technologies of piezoelectric and electromagnetic sound power generation are the two main acoustic-electric conversion technologies nowadays. The piezoelectric sound power generation mainly uses piezoelectric materials as elements of acoustic-electric conversion, while the electromagnetic sound power generation uses the electromagnetic induction methods to achieve the acoustic-electric conversion according to Faraday Law of Electromagnetic Induction. The main research finding of using the piezoelectric sound power generation technology is that by using the ring silicon piezoelectricity of complex diaphragm as the conversion element, S. Horowitz used the micro-mechanical processing technic to make the sound power generator; at the sound pressure level of $149 \mathrm{~dB}$, the maximum density of output electric power can reach $0.34 \mathrm{~W} / \mathrm{cm}^{2}$. If we can further improve the processing design technic, the output electric power density will be $250 \mathrm{~W} / \mathrm{cm}^{2}$.

The domestic research about the noise power generation has begun in the 1980s, and we have achieved certain research findings in this way. For example, Luo Ercang and so on, from Institute of Physical and Chemical Technology of Chinese Academy of Sciences, succeeded in developing the prototype of travelling wave thermoacoustic generator with the hundred Watt level, which was a kind of sound power generation equipment. Iranian researcher invented acoustic wave generation technology, the scientists from University of Utah, USA, invented a thermal-acoustic micro-generator which can transfer thermal energy to acoustic wave and then transfer to available electric power.

The main technical difficult problem of noise power generation is the problems of the acoustic-electric conversion and the noise source. At present, the acoustic-electric conversion technology is becoming more and more mature. The continued high DB noise is produced from the machine equipment in the ship engine room, the sound pressure level of which is about $120 \mathrm{~dB}$ and the noise power can reach $10 \mathrm{~kW}$, so its generating capacity will be more considerable.

The main research findings of using the electromagnetic sound power generation technology is that Tenghsien Lai from Feng Chia University, FCU, designed and made an acoustic wave driven micro-generator with high voltage output, and made the simulation analysis and experimental study to the performance of the generator. The sketch map of the experimental device of the generator is shown as Figure 3. It was made up of the planar coil, the suspension plate with the supporting beam and a permanent magnet. He used the micro-processing technology to make the suspension plate and the planar coil, and integrated a permanent magnetic, and finally completed to assemble the micro-generator by splice. When the acoustic wave produced by the speaker worked on the electromagnetic transducer of this micro-generator, it produced the electric power, which supplied the battery or directly drove the portable electronic device. The result show that the micro-generator with the size of $3 \mathrm{~mm} \times 3 \mathrm{~mm}$ can obtain the maximum induce electromotive force of $0.24 \mathrm{mV}$ with the acoustic wave driven frequency of $470 \mathrm{~Hz}$. If the same micro-generators are placed to a generator matrix, it will have more output electric power; the micro-generator is designed according to the specific acoustic wave driven frequency to make the resonance frequency of the generator correspond to the acoustic wave driven frequency, which can improve the generation efficiency of the generator. 
We take the example of the grassot sound power generation technology, and investigate the generation situation in the ship engine room. The structure diagram of the grassot acoustic-electric transducer is shown as Figure 4 . When the sound pressure $\mathrm{P}$ works on the diaphragm to drive the moving coil to cut the magnetic induction line, the induction electromotive force will be produced in the coil according to Faraday Law of Electromagnetic Induction. The noise energy will be transformed to electric power by the acoustic-electric transducer matrix, and will be sent the controlling adjustment unit to make the rectification regulation, and then will supply the load through the storage battery or directly supply some loads.

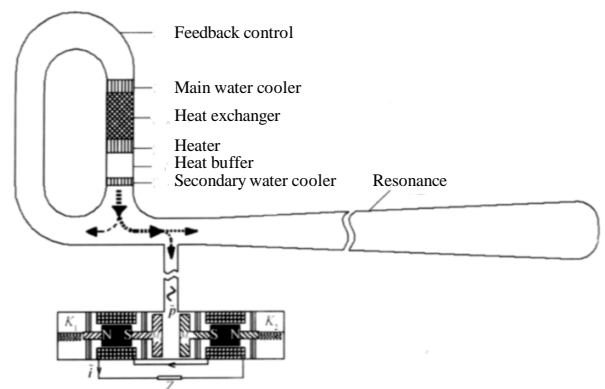

Figure 3 Technical schematic diagram of electromagnetic sound energy power generation

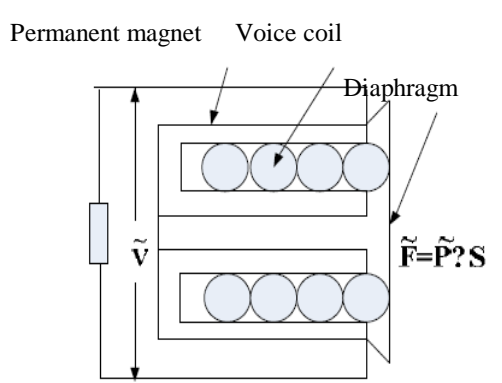

Figure 4 Structure diagram of grassot acoustical-electric transducer

\section{Application discussion}

When the ship is sailing normally, usually one main engine and two generators are working. Now we suppose that the suction and exhaust noise of the main engine and the generator set is $\mathrm{X} 1=\mathrm{X} 2=\mathrm{X} 3=\mathrm{X} 4=100 \mathrm{~dB}$, its noise power is $\mathrm{Y} 1=\mathrm{Y} 2=\mathrm{Y} 3=\mathrm{Y} 4=10 \mathrm{X} / 10(\mathrm{~mW})=1010 \mathrm{~W}=10 \mathrm{~kW}$. Furthermore, the noise of the turbocharger is approximately estimated to be $Y 5=10 \mathrm{~kW}$, the noise power of the whole engine room is $\mathrm{Y}=\mathrm{Y} 1+\mathrm{Y} 2+\mathrm{Y} 3+\mathrm{Y} 4+\mathrm{Y} 5=50 \mathrm{~kW}$ at least.

If the noise energy in the ship engine room is totally transformed to electric power, it will produce $50 \mathrm{kw} \cdot \mathrm{h}$ at least, which is equivalent to the generation capacity of a micro-generator. However, the noise energy cannot be completely received by the acoustic receiver, and on the other side the acoustic-electric transducer studied at present has lower efficiency and less generation capacity, so in order to receive the maximum noise energy in the ship engine room, different acoustic receivers are chosen and installed in the reasonable place in the engine room to receive the maximum noise energy of different frequency bands. According to the sound power micro-generator designed by Tenghsien Lai from Feng Chia University, FCU, the acoustic-electric transducer with the size of $3 \mathrm{~mm} \times 3 \mathrm{~mm}$ can have the maximum induction electromotive force of $0.24 \mathrm{mV}$.

If this electromagnetic micro-transducer is applied in the space of $1 \mathrm{~m}^{2}$ in the ship engine room, its maximum induction electromotive force is $26 \mathrm{~V}$. Given the inconsistency and complexity of the noise in the engine room, if its maximum induction electromotive force is $20 \mathrm{~V}$, and eight one-square-meter micro-generator matrixes are respectively installed around the generator set and the main engine in the ship engine room, and each generator matrix board is series connected, it will get the maximum voltage of $320 \mathrm{~V}$. Given the circuit transmission loss and the power waste of the controlling adjustment unit, the maximum voltage is $250 \mathrm{~V}$ finally, which is shown as Figure 5. 


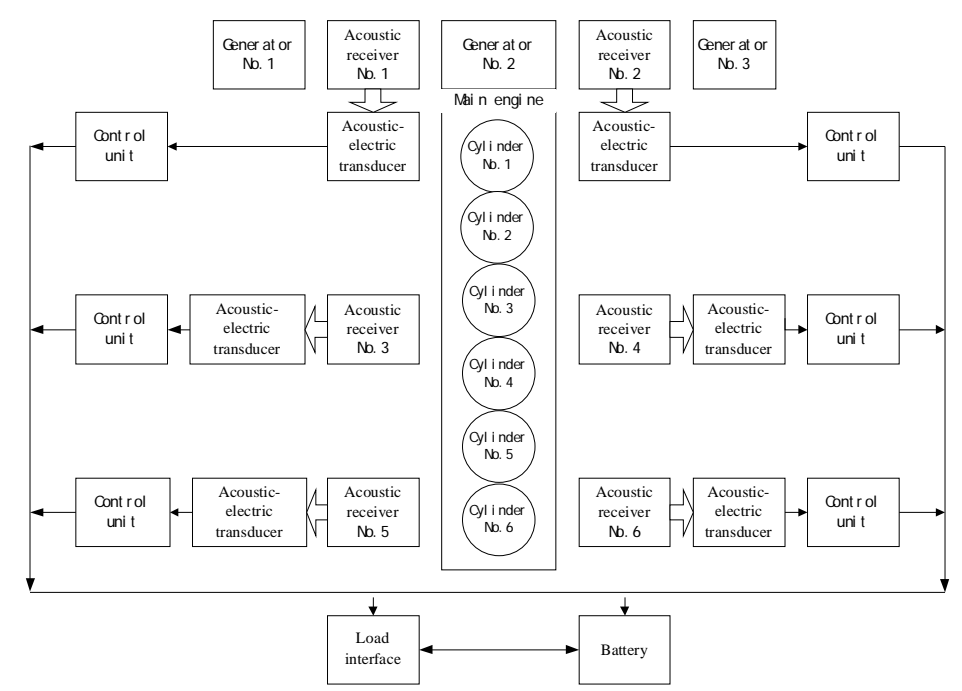

Figure 5 Sketch map of noise power generation system in ship engine rooms

\section{References}

[1] Zhou Fei-yun. Application of Noise Power to the Ship Engine Room. (Marine Electric \& Electronic Engineering, China Classfication Society)08(2012) ;

[2] Wang Shu-xin, Wang Bin, Huang Xin-hua. Noise control of the engine room of marine. (Ship Science an Technology)05(2003);

[3] Xi Gui-Chang. Sound insulation design of ship- - Noise control of engine control room. (Noise and Vibration Control)01( 1982) ; 